\title{
Ingraining Self-Responsibility in Teenagers: An Important Criteria
}

\author{
Syed Jamalullah. R, L.Mary Gladence
}

\begin{abstract}
In today's time, smart phone is available to everyone and has become an integral part of our lives. On the one hand, the advantages are numerous, but on the other hand, the disadvantages are no less. Most often, it is the younger generation which is whiling away its precious time by misusing smart phones. Mobile applications such as videogames or erotic ones, or nasty websites that are rampant in the virtual world are all causing colossal damage to the society, especially to the youngsters, whose blood is buoyant in their veins, which let them give in easily to such shallow and unhealthy interests, thereby resulting in losing their integrity as human beings, which is evident through the dailies. There is a great need to safeguard the lives of the vulnerable young generation with regards to mobile phone usage. Absolute refrainment from the gadgets is not possible as it has other utilities. Therefore, a new approach is proposed here which could supposedly be instrumental in bridling their digital diversions.
\end{abstract}

Keywords: Smart Phones, Mobile Applications, Misuse of MobileApps

\section{INTRODUCTION}

The uses of smart phone have augmented with the flourishing of the internet. According to one research, valuable information constitutes about $90 \%$ of the cumulus of the internet while filthy amassments make up only the rest $10 \%$. Nevertheless, young users are attracted more towards the latter [1] [2]. This paper discusses how the youth, which is the capital of the country, is wasting its time in such menial pursuits, and the possible strategies which could help protect them from the same. The younger generation which should be chasing knowledge and values, is getting devastated by these extraneous digressions. These take the form of addiction and quitting them becomes a daunting task at a later stage. When it concerns video games, it consumes a lot of young people's precious time. They are submerged in it so much so that they fail to keep track of time throughout the day and night. The demerits range not only over losing time but life too. It is recent news that a young boy committed suicide just because his parents did not allow him to play video games [2]. And, when it comes to erotic websites and mobile applications, adultery is becoming widespread. Innocent children become aware of things far ahead of their age and tempt even minors to indulge in obscene acts [3]. Parents worry about how to keep their children's hands off these ingenuous reaches [4].

\section{LITERATURE SURVEY}

One of the previous researches show that, apart from the time-consuming nature of video games, it has also drawn a good amount of wealth from people. It is surprising to know that the money spent on video games is so great in magnitude that it would have been enough to make the country a superpower [3][4]. The statistics are presented below:

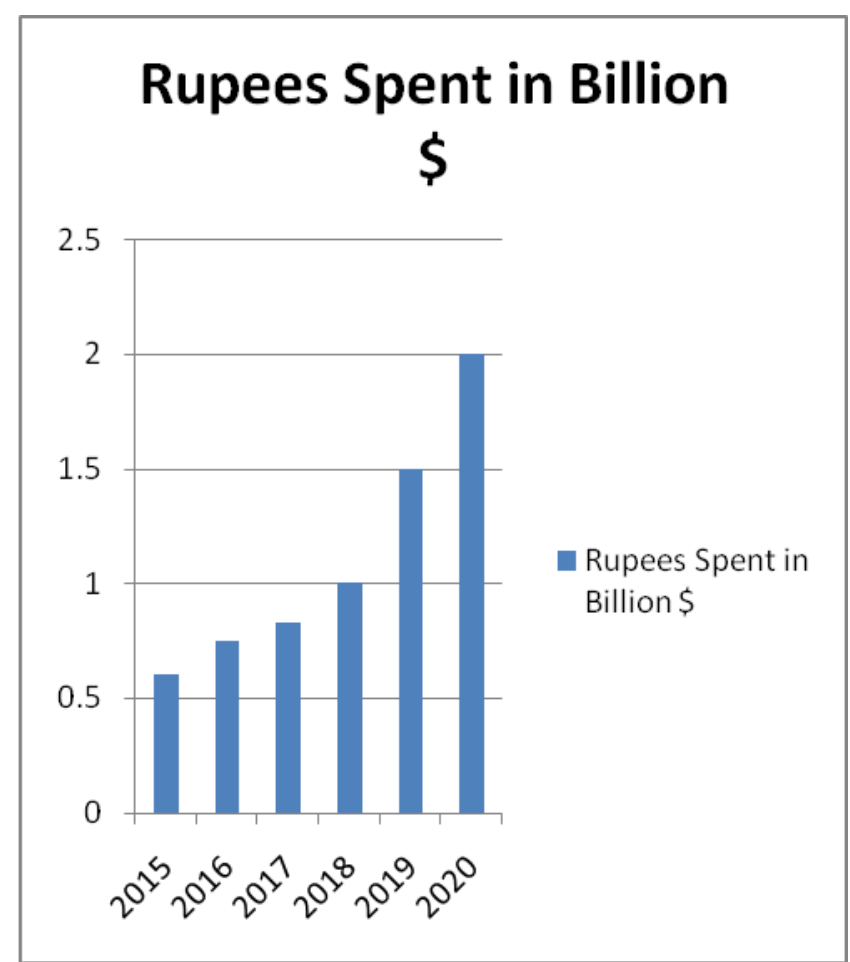

Fig 1: The Amount Spent by Indian Youths for importing video games from $2015-2020$

Concerning vile websites and mobile applications, it is difficult to find an exact count of their number. It is observed largely that those people aged between 18 and 34 are the ones frequenting such resources [4][5]. Data Traffic Analysis highlights the following 10 countries to be topping the list: Concerning vile websites and mobile applications, it is difficult to find an exact count of their number. It is observed largely that those people aged between 18 and 34 are the ones frequenting such resources [4][5]. Data Traffic Analysis highlights the following 10 countries to be topping the list:

Revised Manuscript Received on December 5, 2019.

Syed Jamalullah .R, Research Scholar, School of Computing,

Sathyabama Institute of Science and Technology, Chennai, India.

(Email: syedjamalullahr@gmail.com)

L. Mary Gladence, School of Computing, Sathyabama Institute of Science and Technology, Chennai, India.

(Email: marygladence.it@sathyabama.ac.in)

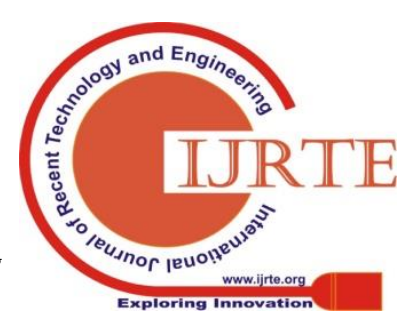




\section{Ingraining Self-Responsibility in Teenagers: An Important Criteria}

The Front Gate List (comprising of 723 words)

The Banned Word List (comprising of 77 words)

The Bad Word List (comprising of 450 words).

\section{Visiting Inappropriate Websites and Apps:}

Children are most vulnerable to stumble upon inappropriate web and app content. In order to have a check upon this, features such as 'Parental Control' were rolled in which allowed the parents to get to know the specific websites visited or mobile applications opened and used by their children, and execute actions such as shutting down or reducing the on-time duration for the concerned resources.

Another method included blocking of web domains which included adult content. Black web Project prepared a list comprising of $6,631,851$ websites to be blocked [5]. Teenagers soon found a way out to access these sites with the help of a tracking application.

\section{PROPOSED REMEDIAL MEASURES}

All the methods tried till date has some limitations. People have easily found ways to escape them. Despite the fact that a number of measures had been taken, it does not seem that a solution has been reached. The reason is that it has been tried to control but failed to instruct. The former measure depends on a system objective to a person.

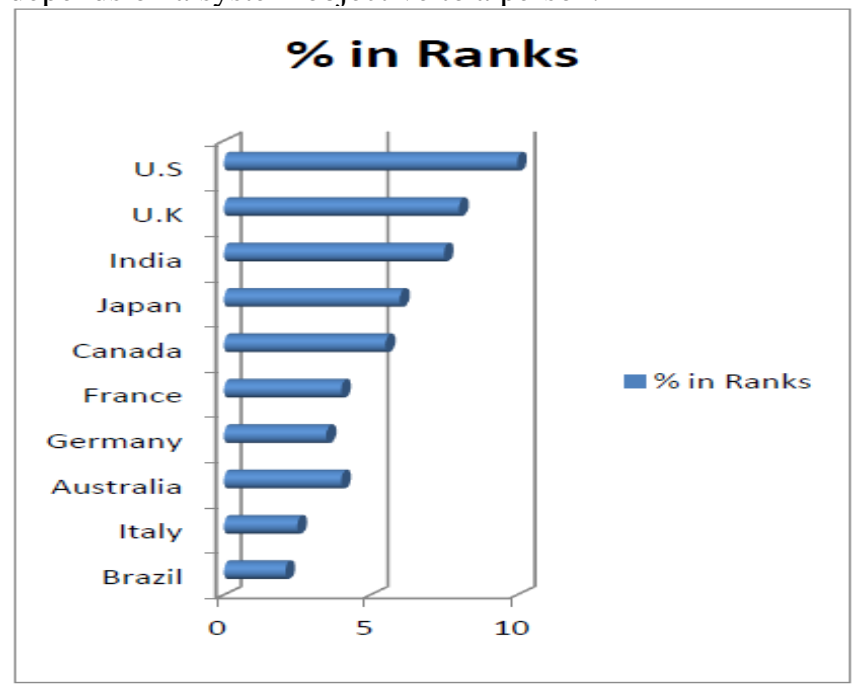

Fig 2: Top 10 Countries which uses nasty websites more

Overall Research Analysis of internet traffic shows that about $60 \%$ of it is directed towards pornographic content [4] [5]. This shows how alarming an issue this is and that there is an exigency for it to be looked into.

There have been numerous researches to identify social problems in digital usage, and formulation of remedies in order to solve them. A brief summary of the same is given below.

\section{OVERVIEW OF EXISTING IMPLEMENTATIONS}

\section{Abuse of Text Messages:}

In today's era, a teenager uses text messages to a great extent. Abuses through this medium include harassment and unhealthy friendship. The method used to control this was by enlisting all the foul words in use and banning them through the Spyware application [4] [5]. Following are the created lists:
It requires the availability of a control system for a given site which only hinders access to it, which otherwise allows access to anyone in the absence of a working software. Finding websites which are ever increasing in number and blocking them across different service providers and browsers seem to be a never ending process. The problem with that is it does not attend to the root cause of such ignoble treading. Youngsters invariably would continue to harbor unhealthy interests. If a way is found to instruct people, it could directly control their usage gauging their conscience which is ever within them. As a result, the users will tend to internalize the need to cultivate healthy habits, thereby letting them make the optimum use of their lifetime. An instance of such an idea is found in other walks of life. Just as cigarette packets have the slogan 'Smoking Kills', the mobile applications or websites under concern shall also show relevant slogans through pop-up windows showing up in regular time intervals of about one minute for a limited duration of about five seconds.

One may argue that it might not be feasible as it will be greatly annoying for the users, but it is seen now-a-days that advertisements have adopted the same way for showing up amidst any readable or viewable content over the web, with people, though grudgingly, accepting it as the status quo unquestioned. Advertisements integrate a great deal of psychological aspects to make them less annoying, at the same time, more captivating whilst it is least expected in the course of viewing or watching user-required content. Similarly considering the aspects, it is necessary to keep messages short, crisp and clear so that it never seems strenuous for the reader to read and understand. Possible examples of such messages could be as follows:

1) Alert! This may be addictive!

2) Alert! This may ruin your time!

3) Alert! This may cause you frustration and anxiety!

4) Alert! This may cause you depression!

Real time messages in video games and other websites could be as follows:
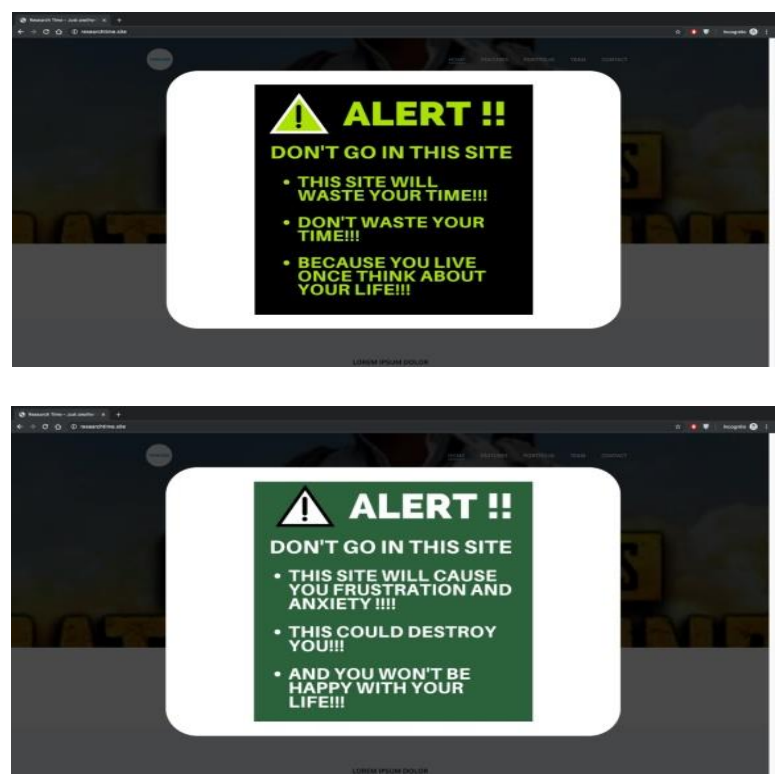

Fig3: Pop Up Windows Shown after each minute in Video games Applications 

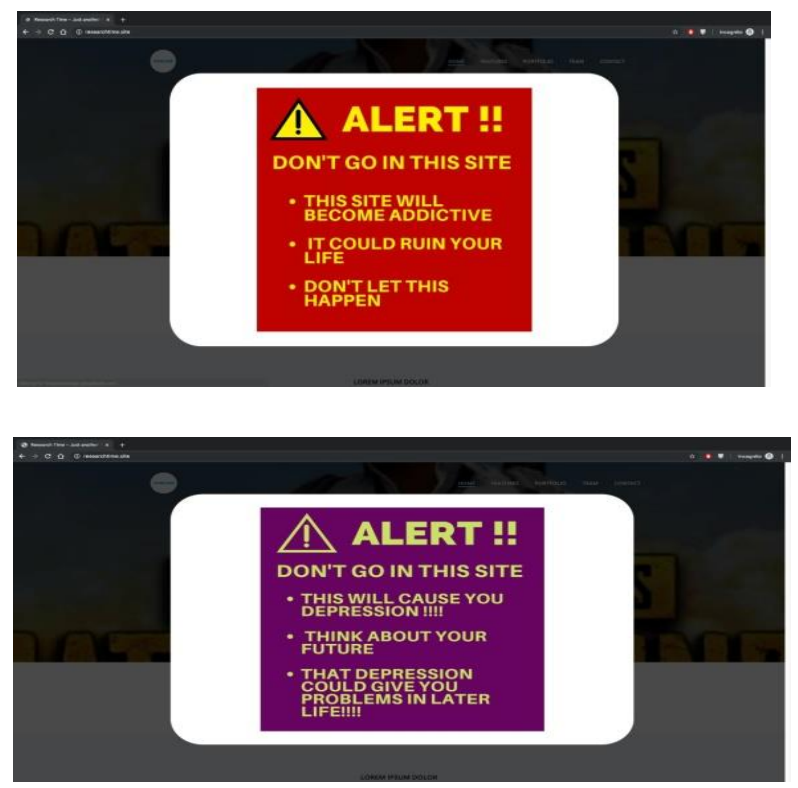

Fig4: Pop Up Window shown after each minute in nasty websites

\section{ANTICIPATED RESULTS}

By adopting the above said method, the youth could be repeatedly informed of the adverse effects of using such filthy websites or mobile applications as many times they visit them. However, if the users are adults, they might know how deleterious it is to use such a digital content. In the case of minors, they would come to know using these timely messages placed rightly at the juncture of the inception of their venture, be it intentional or accidental, and being spread throughout their on-screen activity.

\section{CONCLUSION}

The idea put forth in this paper is aimed at contributing towards social reform, particularly targeting the youth of today. Conscience, or the 'superego' according to psychoanalytic theory, is the governing entity which supersedes basal instincts of human beings which ought to be controlled in order to lead a dignified life. Moreover, these remedies, apart from catering to individual uplifting, would extend towards making good citizens in the context of the nation by curbing the social ills of society, stemming from the barbaric nature of uncultured beings.

\section{REFERENCES}

1. Massimo Marchiori, "The Secure Mobile Teen: Looking at the secret world of children," in 2017 Tenth IEEE International Workshop on Selected Topics in Mobile and Wireless Computing, 2017 , pp. $341-347$.

2. Syafrizal Wardhana, Mira kania Sabariah, ST., MT., Veronikha Effendy, ST., MT., Dana S.Kusumo ST., MT., PhD., " User Interface Design Model for Parental Control Application on Mobile Smart Phone using User Centered Design Method," in 2017 Fifth International Conference on Information and Communication Technology (ICoICT), 2017, pp $349-354$.

3. Ravi Shankar, " A Preliminary Study into the Young Peoples Access to Erotica Websites Through the new Media," in Indian Streams Research Journal, 2012, pp. 975 - 979.

4. Verma, R.K, Mahendra, V.S., "A Gender and Sexual Health Perspective," in Journal of family Welfare, 2004, pp. $71-78$.

5. Shaik S, Rajkumar RP, "Internet Access and Sexual Offences against Children: An Analysis of Crime Bureau Statistics from India," in Open Journal of Psychiatry and Allied Sciences, 2015, pp. 124 - 128. 